\title{
HYBRID TECHNOLOGIES OF WELDING ALUMINIUM ALLOYS BASED ON CONSUMABLE ELECTRODE ARC AND CONSTRICTED ARC*
}

\author{
A.A. GRINYUK ${ }^{2,3}$, V.N. KORZHIK ${ }^{1,2}$, V.E. SHEVCHENKO ${ }^{1,2}$, A.A. BABICH ${ }^{2}$ and S.I. PELESHENKO ${ }^{4}$ \\ ${ }^{1}$ Chinese-Ukrainian E.O. Paton Institute of Welding (Guangdong General Research Institute of Industrial Technology, \\ Guangzhou Research Institute of Non-Ferrous Metals \\ Changxing Str., Tianhe, 510650, Guangzhou, PRC.E-mail: vnkorzhyk@gmail.com \\ ${ }^{2}$ E.O. Paton Electric Welding Institute, NASU \\ 11 Kazimir Malevich Str., 03680, Kiev, Ukraine. E-mail: office@paton.kiev.ua \\ ${ }^{3}$ NTUU «Kiev Polytechnic Institute» \\ 6/2 Dashavskaya Str., 03056, Kiev, Ukraine. E-mail: andrey_grinyuk@ukr.net \\ ${ }^{4}$ South China University of Technology \\ 510641, Guangzhou, PRC. E-mail: sviatoslav@qq.com
}

\begin{abstract}
Main stages of development of equipment and technology of hybrid consumable-electrode plasma-arc (plasma-MIG) welding of aluminium alloys are analyzed. Main design solutions at development of torches for hybrid plasma-MIG welding are shown, i.e. transition from rod anode in hybrid torch plasma part to ring anode. Application of ring anode simplifies the design of hybrid torch for plasma-MIG welding and improves arc contact. The paper presents the advantages of the process of hybrid plasma-MIG welding with coaxial wire feed compared to traditional inert-gas consumable-electrode welding. 23 Ref., 15 Figures.
\end{abstract}

Keyw ords : hybrid plasma-arc welding, consumable electrode, coaxial wire feed, aluminium alloys, constricted arc

Intensive development of high-speed ground-, air- and water-based transport leads to creation of efficient and economically substantiated technologies of producing aluminium alloy welded joints. In the recent decade hybrid technologies of arc welding, combining the energy of nonconsumable electrode constricted arc and consumable electrode arc in one weld pool have been developing intensively. This technology is called hybrid consumable-electrode plasma-arc welding. This process was called Plasma-MIG technology abroad.

Philips Corporation owns the patents for the first hybrid plasmatron with simultaneous application of nonconsumable electrode constricted arc and consumable electrode arc in one pool [1]. Consumable electrode arc runs inside the nonconsumable electrode constricted arc. Schematic of hybrid plasmatron developed by Philips Corporation is shown in Figure 1 . Electrode wire was fed coaxially with constricted arc. Welding was performed at direct current of reverse polarity (DCRP) with tungsten electrode located laterally relative to plasma-forming nozzle axis, used as the cathode. Over the next years, the efforts of Philips
Corporation staff were directed at improvement of the design of hybrid plasmatron with lateral position of tungsten electrode [3].

To ensure compact dimensions of hybrid plasmatron, its cathode and electrode wire were shifted to different sides from the axis of plasmatron proper (Figure 2) [4].

Application of not only transferred, but also nontransferred arc was considered. Different variants of producing nontransferred constricted arc were proposed: between tungsten electrode and compression nozzle; between two tungsten electrodes located side by side; between two tungsten electrodes located at equal distance from electrode wire [5].

Applicability of nontransferred arc was considered not only for constricted arc, but also for consumable electrode arc [6]. Furtheron, application of either nontransferred nonconsumable electrode constricted arc, or nontransferred consumable electrode arc did not become widely accepted, and they are mentioned only in patent publications.

Application of two electrode wires for the process of hybrid plasma-MIG welding was tried out [7].

\footnotetext{
${ }^{*}$ The work was performed with funding from Foreign Experts Program in PRC \#WQ20124400119, R\&D Project of Innovation Group of Guangdong Province \#2010CO104901263 and International Project of the Ministry of Science and Technology of PRC \#2013DFR70160.
} 


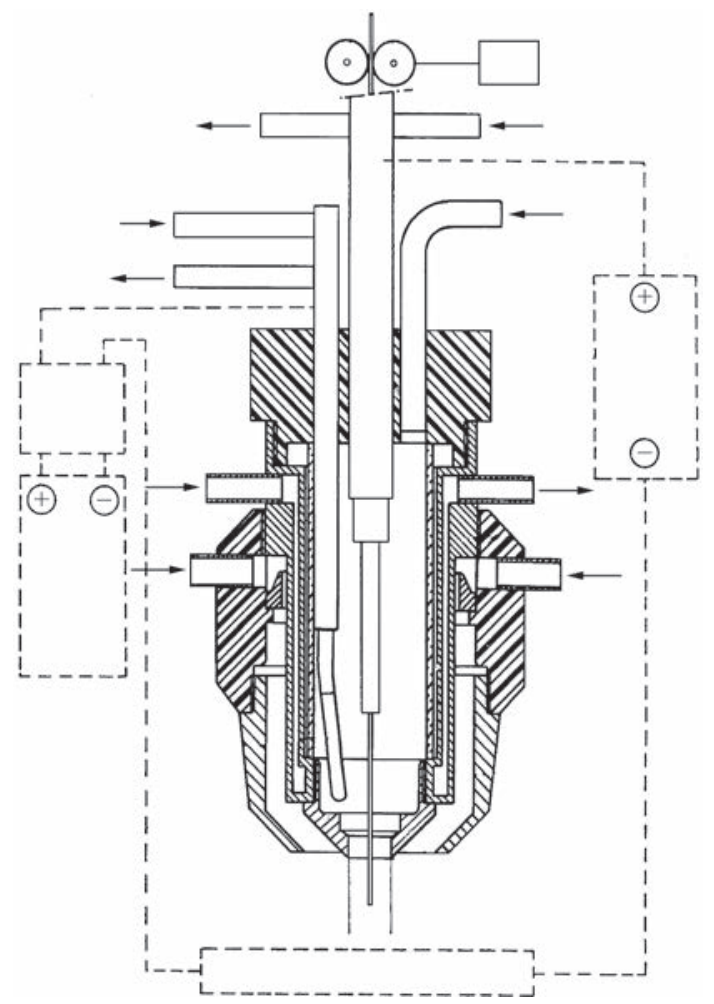

Figure 1. Plasmatron for hybrid plasma-MIG welding developed by Philips Corporation [2]

Designs with lateral position of tungsten anode and current supply to two electrode wires from two different DC power sources, with lateral position of tungsten cathode and coaxial position of split consumable electrode with its powering from one DC source, with tungsten cathode position between the wires of split consumable electrode, as well as application of split consumable electrode and hollow copper cathode operating in the mode of regular DCRP arc generation,

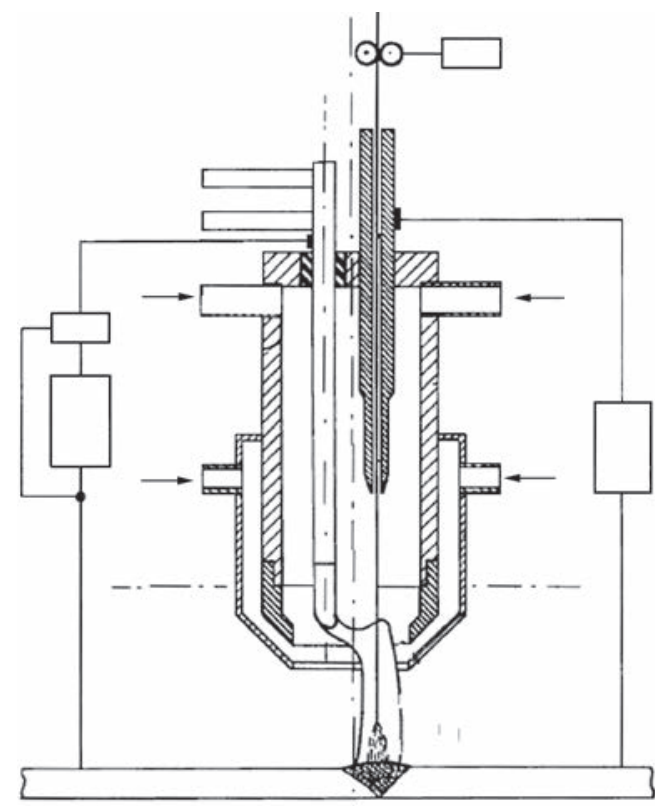

Figure 2. Plasmatron for hybrid plasma-MIG welding with tungsten cathode and electrode wire which are shifted relative to plasmatron axis

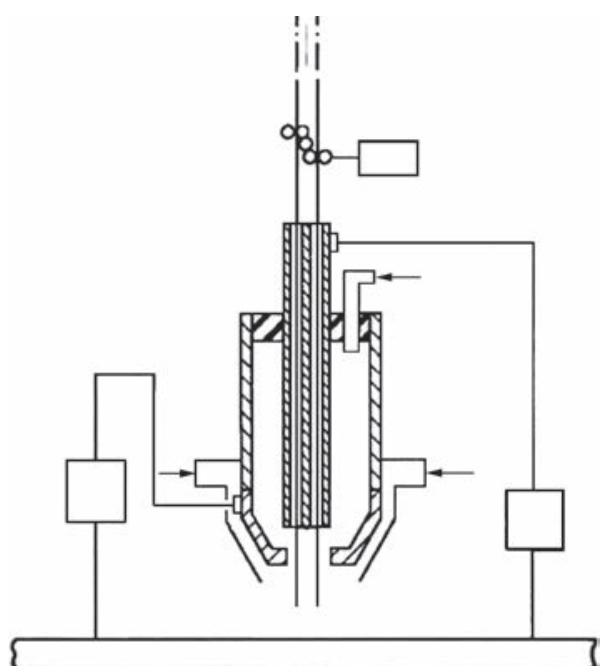

Figure 3. Plasmatron for hybrid plasma-MIG welding with coaxial feed of split electrode through hollow copper cathode operating in the mode of regular nonconstricted arc

were proposed (Figure 3). Such schematics of electrode arrangement were not developed any further.

Variants of simultaneous running into a common pool of regular consumable and nonconsumable electrode arcs with coaxial wire position and hollow anode were proposed $[8,9]$. Figure 4 shows the schematic of a hybrid torch for consumable and nonconsumable-electrode welding. Such a schematic of realization of hybrid process of consumable-electrode welding of aluminium alloys did not become widely accepted.

For realization of the process of hybrid plasma-MIG welding, Philips Corporation developed and batch-produced PZ 4302/10 system (Figure 5). The system consists of power source for DCSP and DCRP

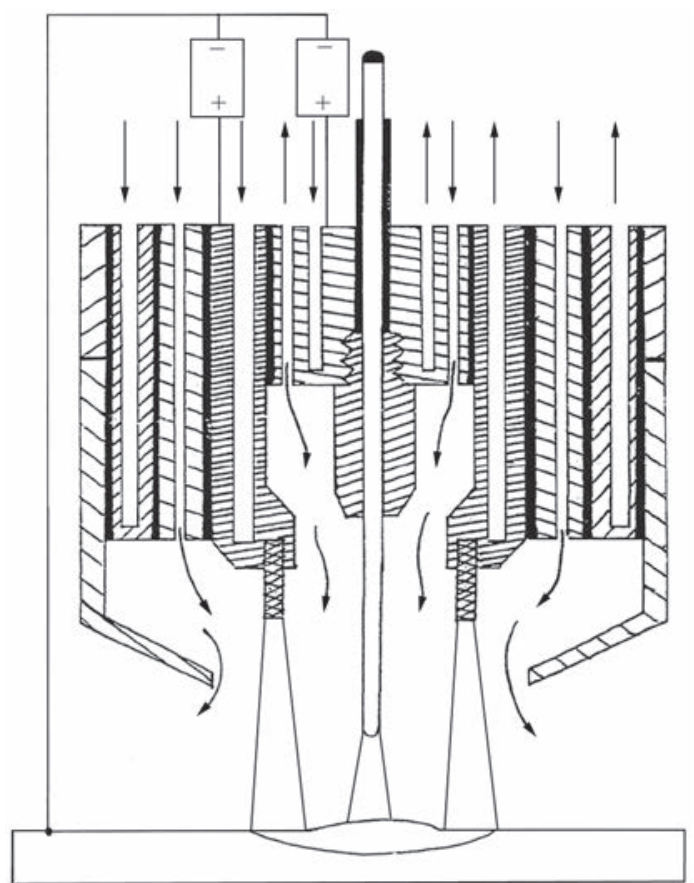

Figure 4. Hybrid torch for consumable and nonconsumable-electrode welding with coaxial wire feed through circular cathode 


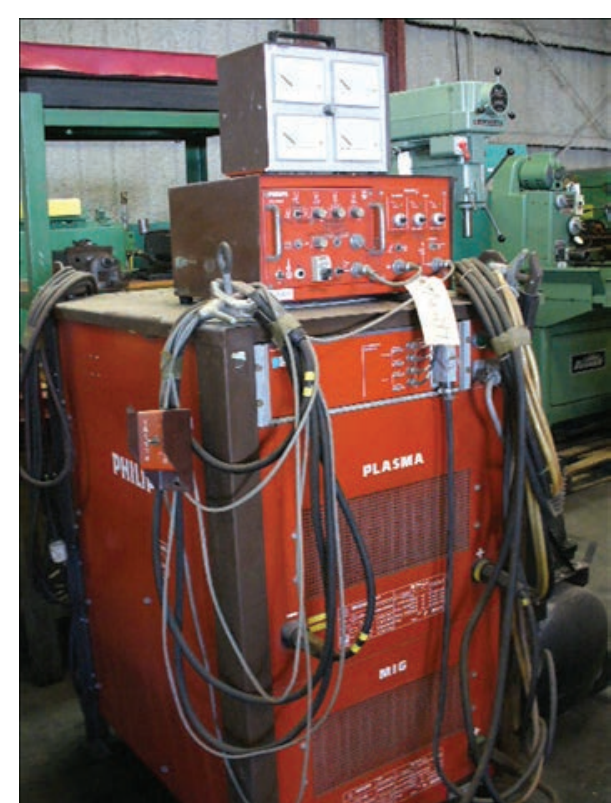

Figure 5. PZ 4302/10 system for hybrid plasma-MIG welding developed by Philips Corporation

plasma-arc welding, DC power source for consumable-electrode welding (both the power sources are installed in one case), electrode wire feed mechanism and control system. This system provided maximum current of 400 A for DC plasma-arc welding and $630 \mathrm{~A}$ for consumable-electrode welding. There is no information about the hybrid plasmatron, with which this system was fitted.

The issue of simultaneous running of nonconsumable electrode constricted arc and consumable-electrode arc positioned in sequence one after the other was also considered $[10,11]$. Plasma Laser Technologies Ltd. is the main developer of equipment for hybrid plasma-MIG welding with serial arrangement of nonconsumable electrode constricted arc and consum-

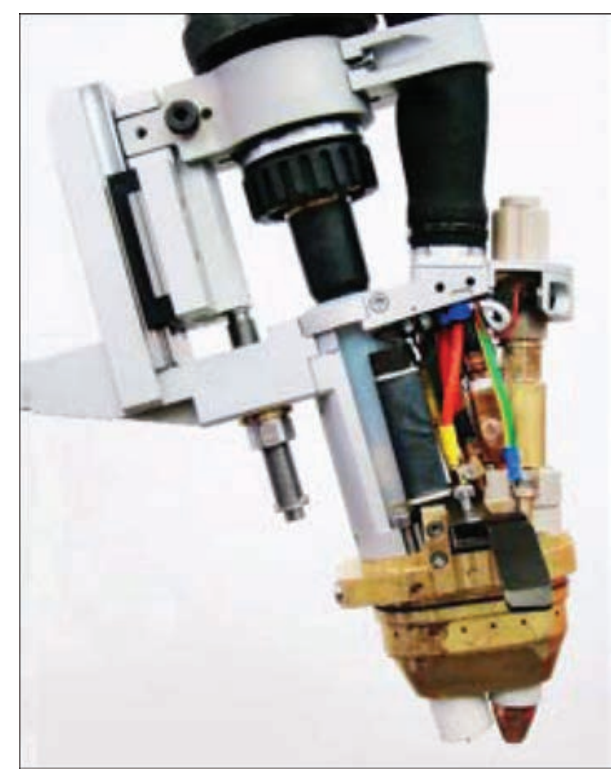

Figure 6. Plasma Laser Technologies hybrid torch for plasma-MIG welding of aluminium alloys able electrode arc. The process of hybrid plasma-MIG welding developed by this company received patented name of Super-MIG. Consumable electrode torch and plasmatron are located in one case and have one common protective nozzle. To weld materials, having no oxides on their surface with melting temperature above that of base metal, DCSP nonconsumable electrode constricted arc and DCRP consumable electrode arc are used. So-called electromagnetic shield is additionally incorporated into the hybrid plasmatron design to prevent electromagnetic interaction of the arcs. A special torch was developed for hybrid welding of aluminium alloys. It supports plasma-arc welding by different polarity asymmetrical current of up to $200 \mathrm{~A}$ and consumable-electrode welding at up to 550 A DCRP current (Figure 6). Equipment complex Super-MIG for hybrid plasma-MIG welding also includes plasma module with equipment complex control system. Control system allows connection to welding robot controllers.

Super-MIG process allows simplifying the hybrid plasmatron design, compared to schematic of coaxial feed of electrode wire, but here the consumable electrode arc is not additionally constricted by nonconsumable electrode constricted arc that causes stronger metal spatter and lower penetrability. Further development of hybrid torches for plasma-MIG welding went along the path of hollow anode introduction [12-15]. The anode was of composite design with refractory material insert.

Hybrid plasmatron of Merkle Company (Germany) is also designed by the schematic of application of ring hollow anode and coaxial feed of electrode wire [16]. Merkle serial power sources for consumable-electrode welding were used as power sources for generation of plasma and consumable electrode arc. A feature of Merkle hybrid torch for plasma-MIG welding is bimetal composite anode (Figure 7). The anode lower part is made from refractory material and is brazed to copper water-cooled part.

Chemnitz Technical University (Germany) developed a device, providing switching on and simultaneous operation of power sources for DCRP nonconsumable-electrode plasma-arc welding and power source for DCRP consumable-electrode welding [17]. Research in the same direction is performed also at SLV Muenchen (Germany). Similar research is performed at Perm State University (Russia) [18, 19]. In Ukraine plasma-MIG welding was studied at Priazovsky Technical University [20]. Features of plasma-MIG welding process were also studied in China and Brazil [21, 22].

TBI Company (Germany) produces customized PLM 500 and PLM 600 torches with ring anode for 


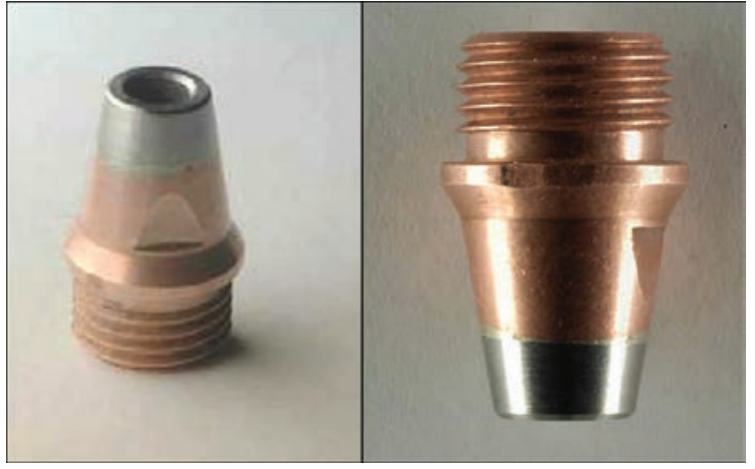

Figure 7. Composite anode of Merkle hybrid torch for plasma-MIG welding with coaxial wire feed

hybrid plasma-MIG welding, which can stand total current load from 500 up to 600 A DCRP, respectively (Figure 8). Solid copper anode is the feature of the design of the torch for hybrid plasma-MIG welding of TBI Company. Plasma-forming nozzle and protective gas nozzle in this design are made as one solid part, making the design more complicated and increasing the part cost.

Hybrid 8000 MR system (AMT Maschinen- und Geraetetechnik GmbH, Germany) provides simultaneous generation of DCRP for nonconsumable electrode constricted arc and for consumable electrode arc (Figure 9). Welding current adjustment for each of the arcs is performed individually in the range from 15 up to $400 \mathrm{~A}$. This system can be also used as regular power source for consumable-electrode welding. When this system is applied, nonconsumable electrode constricted arc is excited without using the pilot arc. Application of this system for DC nonconsumable-electrode plasma-arc welding is somewhat difficult, as availability of pilot arc and oscillator for igniting it is not envisaged.

DigiPlus A7PM system (ICM Soldagem, Brazil) provides a similar range of welding functions as AMT Company system. This system also cannot be used for regular nonconsumable-electrode plasma-arc welding for the reason of absence of the module of pilot arc ignition and generation.

A number of all-purpose equipment complexes for plasma-arc, combined and hybrid welding have been developed within the framework of PWI co-operation under a project of Chinese-Ukrainian Welding Institute, and produced by «Science-Production Center «PLAZER Ltd.» (Ukraine). The basic concept of these complexes development is upgrading and adaptation of batch-produced power sources for nonconsumable and consumable-electrode welding. These equipment complexes allow implementation of a wide range of plasma and arc processes: performing DCSP plasma-arc welding with filler wire and welding by asymmetrical current of different polarity, hybrid plasma-MIG welding with plasmatron ring anode

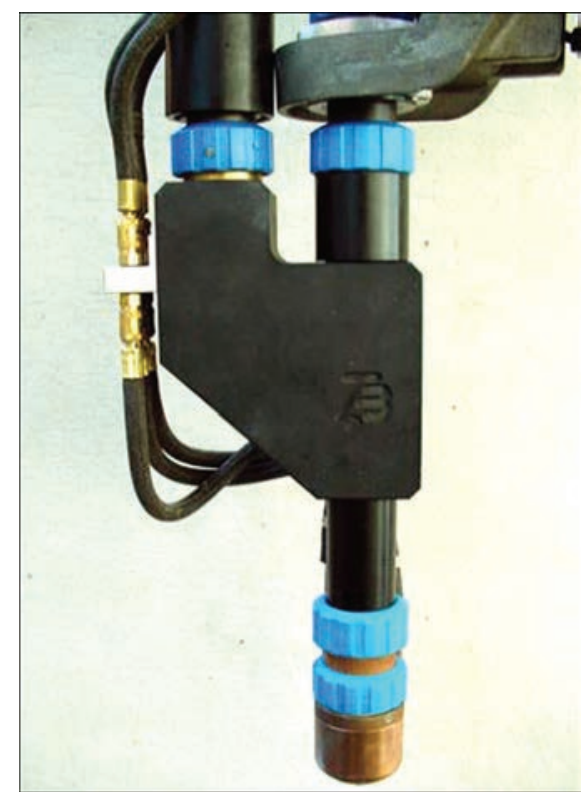

Figure 8. PLM 500 torch of TBI Company for hybrid plasma-MIG welding

and axial feed of electrode wire, combined constricted arc and consumable-electrode welding in «soft plasma» mode, automatic consumable and nonconsumable-electrode welding [23]. This equipment is made of modular design to enable realization of such a set of technological capabilities.

In addition, this equipment supports operation in a complex both with different types of welding manipulators (system for longitudinal welding, columns, rotators, etc.), and with welding robots. For this purpose, the control system has an interface for connection to a robot, with communications protocols, applied for welding robots of leading manufacturers.

Equipment complex PLAZER PW-HYBRID TC (Figure 10) allows performing welding in the downhand position, vertical and horizontal welds on vertical and inclined planes. Availability of rotary welding

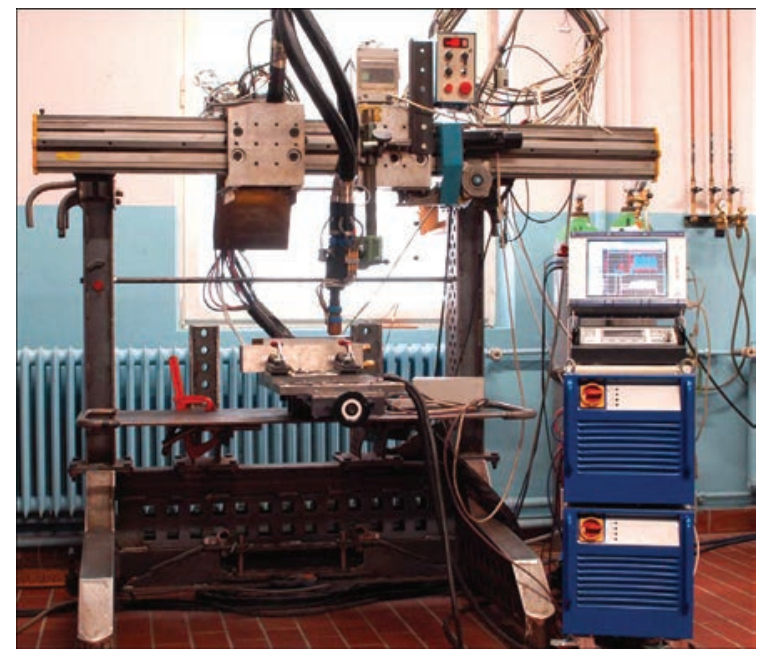

Figure 9. Hybrid 8000 MR system for hybrid plasma-MIG welding with axial feed of electrode wire of AMT Company 


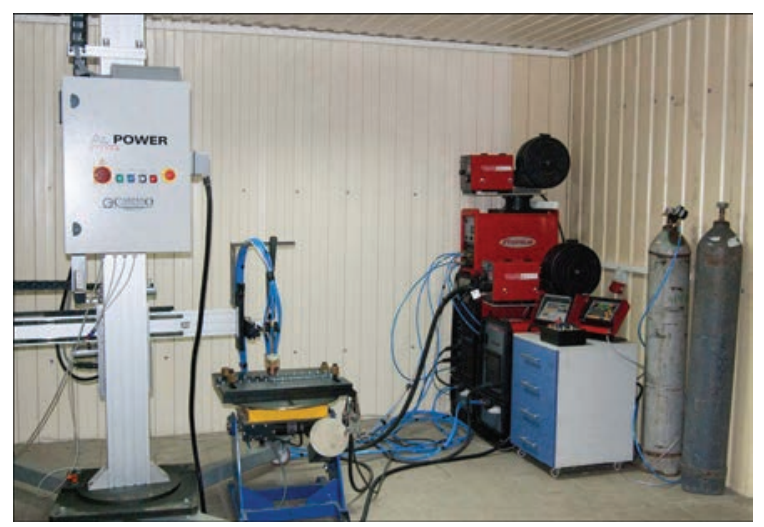

Figure 10. All-purpose equipment complex PLAZER PW-HYBRID TC for nonconsumable-electrode plasma-arc welding, combined and hybrid plasma-arc welding in different spatial positions

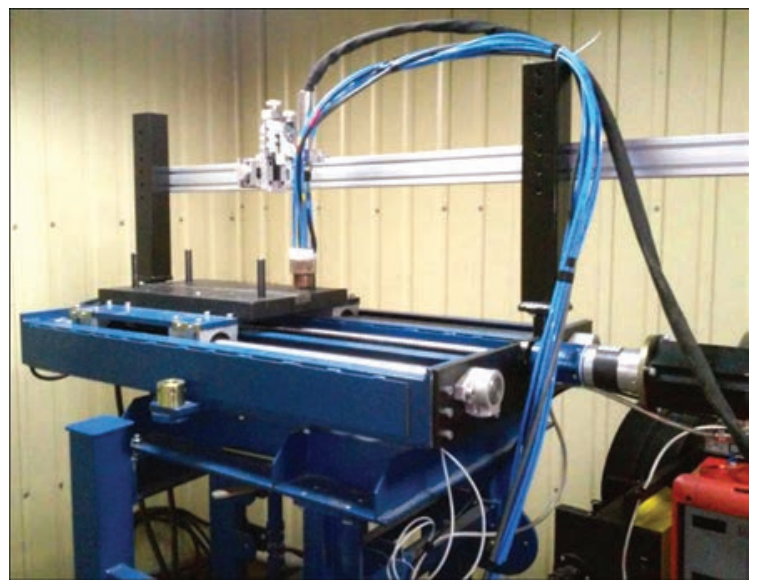

Figure 11. PLAZER all-purpose assembly-welding table for welding downhand welds, vertical and horizontal welds on vertical and inclined planes

positioner in its composition, allows performing circumferential welds.

For fitting a welding research section, SPC «PLAZER», developed an all-purpose assembly-welding table by PWI technical assignment. A feature of this table design is movement of the part proper, and not of welding torches. This eliminates the factor of torch oscillation,

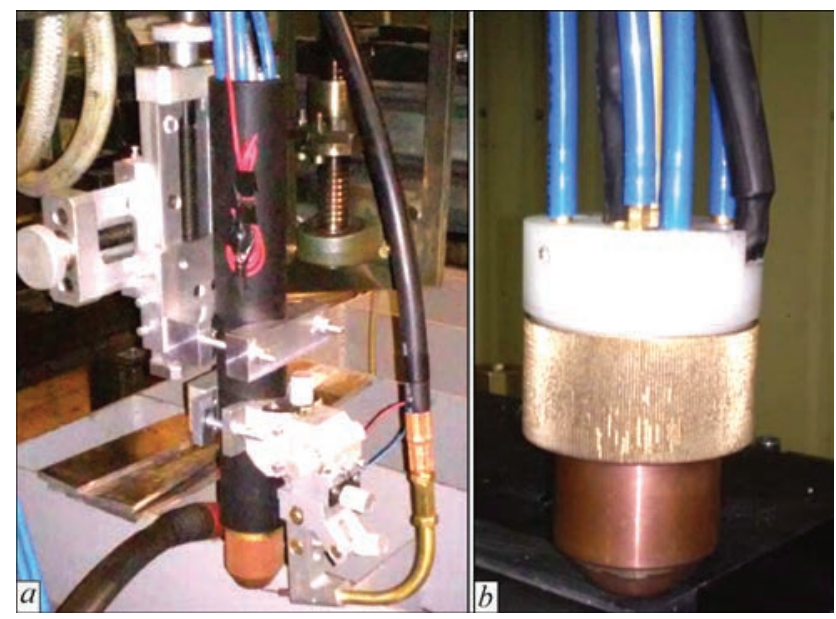

Figure 12. Plasmatrons developed by PWI for nonconsumable-electrode plasma-arc ( $a$ ) and hybrid plasma-MIG welding $(b)$

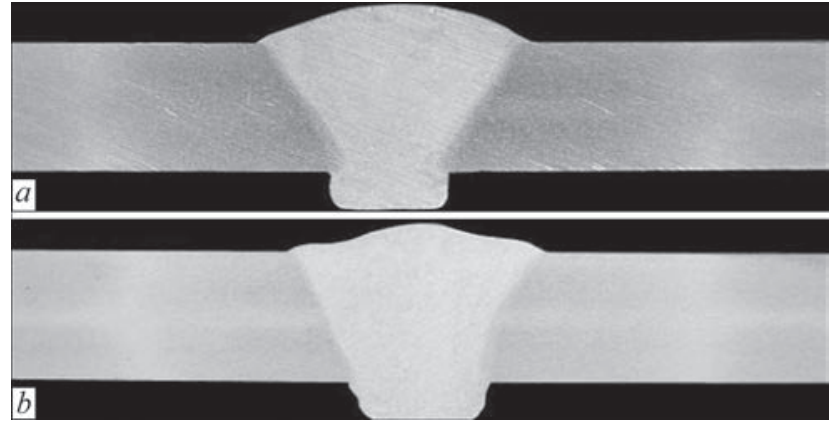

Figure 13. Transverse macrosections of welded joints of aluminium alloy $50838 \mathrm{~mm}$ thick made by consumable-electrode welding at $5 \mathrm{~mm} / \mathrm{s}$ speed $(a)$ and by hybrid plasma-MIG welding $(b)$

that allows a more accurate evaluation of electrical parameters influence on arcing. Special mechanisms provide the possibility of moving the table into different spatial positions to perform vertical and horizontal welds on vertical and inclined planes (Figure 11).

All-purpose equipment complexes for nonconsumable and consumable-electrode plasma-arc welding developed at PWI are fitted with control system based on PLC controller and respective software. This solution enables development of welding complexes based on serial power sources for consumable and nonconsumable-electrode arc welding. Application of a wide range of controllers, both with digital and with analog inputs-outputs enables application of welding equipment of different manufacturers fitted with connectors for data exchange by digital protocols or having only analog inputs-outputs.

All the all-purpose equipment complexes are fitted with plasmatrons for nonconsumable and consumable-electrode welding developed by PWI (Figure 12).

Application of hybrid plasma-MIG welding for joining aluminium alloy 5083, compared to regular consumable-electrode welding, enabled reducing welding consumables consumption for weld for-

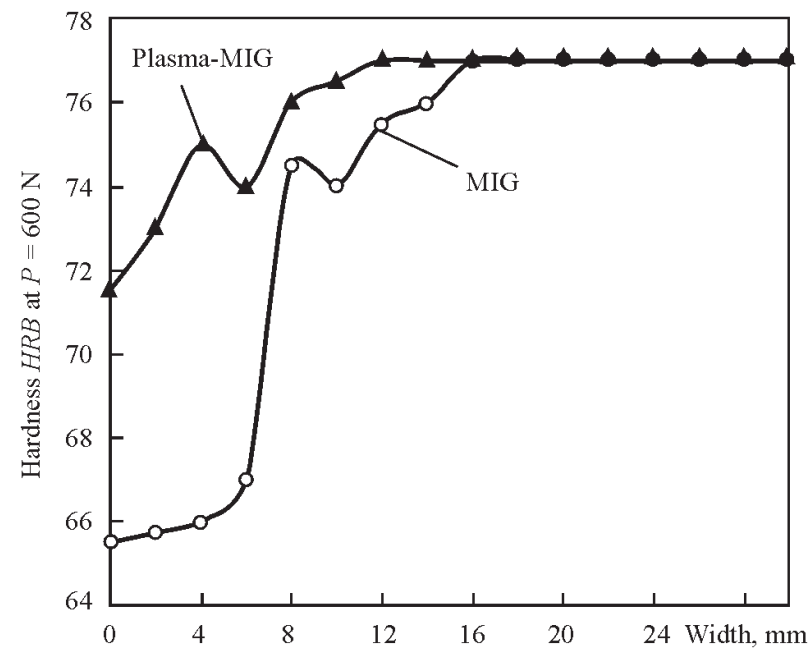

Figure 14. Transverse hardness distribution of MIG-welded joints of aluminium alloy $50838 \mathrm{~mm}$ thick at $5 \mathrm{~mm} / \mathrm{s}$ speed and by hybrid plasma-MIG welding at $6.7 \mathrm{~mm} / \mathrm{s}$ speed 
mation, lowering electrode metal spatter, increasing welding speed, and reducing the width of the weld (Figure 13) and base metal softening zone (Figure 14).

More concentrated heating and increase of welding speed at application of hybrid plasma-MIG welding technology, compared to consumable-electrode welding, lead to an increase of both strength coefficient of the welded joint (from 0.90 to 0.95 ) and of weld metal (from 0.80 to 0.85 ) (Figure 15).

\section{Conclusions}

The most promising direction of development of plasma-arc welding of aluminium alloys is combined and hybrid application of two and more heat sources at welded joint formation. This allows increasing the welding speed, reducing electrode metal spatter, and lowering the level of welded structure distortion. One of the promising directions is hybrid plasma-MIG welding with ring cathode and axial feed of electrode wire.

There exist two main directions of development of equipment for hybrid plasma-MIG welding: development of specialized systems or of complex of equipment based on serial power sources for nonconsumable and consumable-electrode welding. For research laboratories, development of equipment complexes and not development of specialized systems is promising in the first place. Such an approach will allow a wider application of power sources capabilities, incorporated into their design, and flexible combination of different heat sources.

For plant conditions, it is possible to develop an equipment complex, proceeding from the anticipated product range, i.e. at maximum fast change of manufactured product range, provide power sources and software for the control system with broader technological capabilities.

Application of hybrid plasma-MIG welding, compared to regular consumable-electrode welding, allows increasing process efficiency, lowering electrode wire consumption, reducing the width of base metal softening zone, lowering spatter and improving the weld strength values.

1. Lieikens, A.C.H.J., Essers, W.G. Method of and device for plasma arc welding. Pat. 3,612,807 US. Int. Cl. B23k9/00. Publ. 1971.

2. Essers, W.G., Jelmorini, G. Method of plasma-MIG welding. Pat. 3,891,824 US. Int. Cl. B23k9/00. Publ. 1975.

3. Essers, W.G. Method of and device for arc welding. Pat. 4,039,800 US. Int. Cl. B23k9/00. Publ. 1977.

4. Essers, W.G. Method of and device for plasma-MIG-welding. Pat. 4,233,489 US. Int. Cl. B23k9/00. Publ. 1980.

5. Essers, W.G., Jelmorini, G., Tichelaar, G.W. Method of and device for arc welding. Pat. 4,174,477 US. Int. Cl. B23k9/00. Publ. 1979.

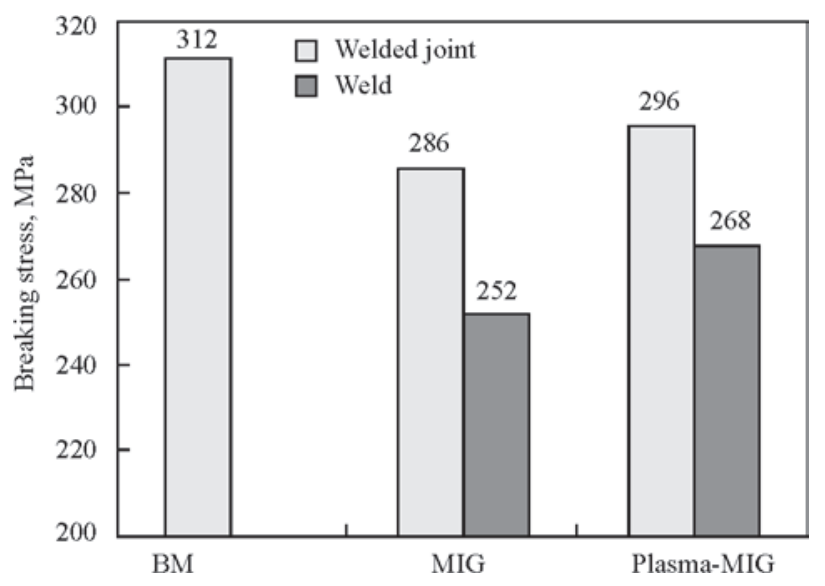

Figure 15. Strength of flat samples of base metal and welded joints of aluminium alloy $50838 \mathrm{~mm}$ thick produced by MIG welding at $5 \mathrm{~mm} / \mathrm{s}$ speed and by hybrid plasma-MIG at $6.7 \mathrm{~mm} / \mathrm{s}$ speed

6. Essers, W.G. Method of and device for arc welding. Pat. 4,039,800 US. Int. Cl. B23k9/00. Publ. 1977.

7. Jelmorini, G. Method and device for plasma-MIG welding. Pat. 4,147,919 US. Int. Cl. B23k9/00. Publ. 1979.

8. Manz, A.F. Method and torch for sustaining multiple coaxial arcs. Pat. 4,048,465 US. Int. Cl. B23k9/00. Publ. 1977.

9. Brabader, W.A.J. Welding torch. Pat. 2004/0188406A1 US. Int. Cl. B23k9/173. Publ. 2004.

10. Lin Zhang, Timm Matus. Plasma-MIG welding with plasma torch and with MIG torch. Pat. 6,693,252 US. Int. Cl. B23k10/00. Publ. 2004.

11. Ignatchenko, G., Dykhno, I. MIG-plasma welding. Pat. 2005/0199593A1 US. Int. Cl. B23k9/12. Publ. 2005.

12. (2007) Hybrid welding: An alternative to SAW. Welding J., 10, 42-45.

13. Blechert, P. Schweissbrenner zum Plasma-MIG-Schweissen. Pat. 0168810A1 EP. Int. Cl. B23k28/00. Publ. 1985.

14. Kaika, V.I., Kutyr, A.S., Merkhin, V.M. et al. Plasmotron for consumable-electrode welding. USSR author's cert. 1557833A1. Int. Cl. B23k9/16. Publ. 1992.

15. Kaika, V.I., Ronsky, V.L., Kuzmenkov, L.G. et al. Method of consumable-electrode plasma welding and plasmotron. USSR author's cert. 1816250A3. Int. Cl. B23k10/00. Publ. 1993.

16. Merkle, W. Plasma-MIG/MAG-Schweissbrenner. Pat. 10327911A1 DE. Int. Cl. B23k10/02. Publ. 20.01.2005.

17. Matthes, K.-J., Kusch, M. (2000) Plasma-MIG-Schweissen. Praktiker, 5, 182-188.

18. Shchitsyn, Yu.D., Tytkin, Yu.M. (1986) Plasma consumable-electrode welding of aluminium alloys. Svarochn. Proizvodstvo, 5, 1-2.

19. Shchitsyn, Yu.D., Shchitsyn, V.Yu., Herold, H. (2003) Plasma welding of aluminium alloys. Ibid., 5, 36-42.

20. Makarenko, N.A., Nevidomsky, V.A. (2003) Thermal cycles in plasma-MIG surfacing. The Paton Welding J., 1, 43-45.

21. Bai Yan, Gao Hong-Ming, Qiu Ling (2010) Droplet transition for plasma-MIG welding on aluminium alloys. Transact. of Nonferrous Met. Soc. China, Vol. 20, 2234-2239.

22. da Cunha, T.V., Dutra, J.C. (2007) Processo plasma-MIG contribuicao do arco plasma na capacidade de fusao do arame. Soldagem Insp. Sao Paulo, 12(2), 89-96.

23. Grinyuk, A.A., Korzhik, V.N., Shevchenko, V.E. et al. (2015) Main tendencies in development of plasma-arc welding of aluminium alloys. The Paton Welding J., 11, 31-41.

Received 18.04.2016 